\title{
PENERAPAN TRANSFORMASI DATA DISCRETE WAVELET TRANSFORM PADA NEURAL NETWORK UNTUK PREDIKSI HARGA SAHAM
}

\author{
Indah Suryani \\ Teknik Informatika \\ STMIK Nusa Mandiri Jakarta \\ indah.ihy@nusamandiri.ac.id
}

\begin{abstract}
Abstrak
Penelitian mengenai harga saham memang masih menarik bagi para peneliti. Seperti halnya dalam penelitian ini, data penutupan harga saham ANTM dijadikan sebagai set data yang diolah untuk kemudian dilakukan prediksi harga kedepannya. Adapun metode Neural Network merupakan metode yang sangat banyak digunakan peneliti karena berbagai keunggulannya. Sedangkan metode Discrete Wavelet Transform digunakan untuk melakukan transformasi data. Penggunaan transformasi data menggunakan Discrete Wavelet Transform diharapkan dapat meningkatkan kualitas data sehingga dapat meningkatkan performa Neural Network. Adapun berdasarkan eksperimen yang dilakukan dengan metode Neural Network dengan fungsi aktivasi Binary Sigmoid menunjukkan hasil RMSE 0,024 sampai dengan 0,022. Sedangkan dari hasil eksperimen Neural Network dengan fungsi aktivasi Binary Sigmoid yang dilakukan transformasi data dengan Discrete Wavelet Transform, telah menghasilkan RMSE yang lebih kecil daripada Eksperimen prediksi yang tanpa menggunakan transformasi data dengan Discrete Wavelet Transform yaitu 0,02 sampai dengan 0,018. Dari hasil perbandingan RMSE tersebut, terdapat selisih nilai rata-rata RMSE sebesar 0,0039. Artinya penerapan transformasi data menggunakan Discrete Wavelet Transform ini ternyata mampu meningkatkan performa prediksi dengan Neural Network yaitu dengan menghasilkan nilai error yang lebih kecil atau menghasilkan prediksi yang lebih akurat.
\end{abstract}

Kata kunci: Prediksi, Harga Saham, Neural Network, Discrete Wavelet Transform

\begin{abstract}
Research on stock prices is still interesting for researchers. As in this study, ANTM's stock price closing data is used as a data set that is processed and then predicted in the future. The Neural Network method is a method that is very widely used by researchers because of its various advantages. While the Discrete Wavelet Transform method is used to perform data transformation. The use of data transformation using Discrete Wavelet Transform is expected to improve data quality so that it can improve Neural Network performance. The experiment based on the Neural Network method with the Binary Sigmoid activation function shows the results of RMSE from 0.024 to 0.022 . While the results of Neural Network experiments with the Binary Sigmoid activation function which carried out data transformation with Discrete Wavelet Transform, has produced a smaller RMSE than Prediction Experiments without using data transformation with Discrete Wavelet Transform that is 0.02 to 0.018. From the results of the RMSE comparison This, there is a difference in the average value of RMSE of 0.0039. This means that the application of data transformation using Discrete Wavelet Transform turns out to be able to improve the performance of predictions with Neural Networks by producing smaller error values or producing more accurate predictions.
\end{abstract}

Keywords: Prediction, Stock Prices, Neural Network, Discrete Wavelet Transform

\section{PENDAHULUAN}

Prediksi pasar saham selalu menjadi hal yang menarik bagi para peneliti (Rajput \& Bobde, 2016). Sejalan dengan pendapat (A, Adebiyi, K, Charles, 0, Marion, \& O, Sunday, 2012) bahwa prediksi harga saham dengan teknik Datamining adalah salah satu masalah terpenting dalam keuangan yang diselidiki oleh para peneliti di seluruh dunia. Data harga saham merupakan data kuantitatif yang termasuk ke dalam data time series. Time series merupakan satu set pengamatan kuantitatif yang diatur dalam urutan kronologis (Kirchgässner \& Wolters, 2007). Time series plots dapat mengungkapkan pola seperti random, tren, pergeseran tingkat, periode atau siklus, pengamatan yang tidak biasa atau kombinasi dari pola (Montgomery, 2008). 
Dalam berbagai bidang penelitian, metode Neural Network merupakan salah satu metode yang paling banyak digunakan oleh para peneliti. Manfaat utama dari penggunaan Neural Network (Bennett, Stewart, \& Lu, 2014) adalah kemampuannya untuk menggeneralisasi, mengidentifikasi hubungan non-linear dan penerapan ke berbagai aplikasi. Sebagai approximators dan sistem pembelajaran yang fleksibel, jaringan saraf telah menarik meningkatnya minat dalam menggunakan mereka untuk pemodelan dan peramalan runtun waktu (Ouyang \& Yin, 2014).

Discrete Wavelet Transform mirip dengan Discrete Fourier Transform dan banyak digunakan dalam aplikasi praktis. Prinsipnya tetap sama dengan transformasi lainnya. Sinyal diubah menjadi bentuk yang berbeda menggunakan fungsi dasar yang lebih cocok untuk pemrosesan yang diperlukan, dan transformasi dapat dilakukan secara efisien menggunakan algoritma cepat (Sundararajan, 2015). Haar Discrete Wavelet Transform adalah Wavelet paling sederhana diantara berbagai jenis Wavelet.

Beberapa penelitian terkait dengan topik yang diangkat dalam penelitian ini diantaranya adalah penelitian yang dilakukan oleh (A, Adebiyi et al., 2012) yang menyajikan pendekatan hibdrida dari kombinasi variabel terhadap analisis teknis dan analisis fundamental untuk membuat model prediksi Feed Forward Multilayer Perceptrom Neural Network yang dilatih menggunakan algoritma Backpropagation untuk meningkatkan akurasi prediksi harga saham. Pada hasil empirisnya menunjukkan level akurasi tinggi untuk prediksi harga saham menggunakan pendekatan hibrida ternyata lebih baik dari pendekatan analisis teknis.

Dalam penelitiannya (Anbazhagan \& Kumarappan, 2014) mengangkat mengenai perlunya proses pra pengolahan data untuk mengekstrak informasi berlebihan dari sinyal asli. Dalam penelitiannya dilakukan proses pra pengolahan data dengan menggunakan metode Discrete Cosine Transform untuk meningkatkan efisiensi pembelajaran pada Feed Forward Neural Network. Hasilnya menunjukan bahwa model ini menunjukkan kompleksitas dan waktu komputasi yang lebih rendah jika dibandingkan dengan 17 model lainnya.

Selain itu penelitian (Suryani, 2015) juga menunjukkan peningkatan terhadap evaluasi nilai Root Mean Square Error (RMSE) terhadap prediksi harga emas dengan menggunakan metode Neural Network yang sebelumnya dilakukan transformasi data menggunakan Exponential Smoothing.
Salah satu keterbatasan metode penelitian adalah bahwa mereka mengabaikan potensi transformasi untuk meningkatkan perkiraan (Beaumont, 2014). Maka Berdasarkan hasil penelitian terkait, pada penelitian ini dilakukan penerapan transformasi data menggunakan Discrete Wavelet Transform yang diharapkan dapat meningkatkan performa dari metode Neural Network dalam melakukan prediksi harga saham ANTM.

\section{METODE PENELITIAN}

\section{Jenis Penelitian}

Penelitian ini meerupakan penelitian kuantitatif berupa penelitian eksperimental.

\section{Data dan Teknik Pengumpulan Data}

Data yang digunakan dalam penelitian ini adalah data saham perusahaan Aneka Tambang Persero, Tbk. Data tersebut berupa data historis harga saham ANTM yang dikumpulkan dari data sekunder yang diambil dari situs web. Data saham ANTM yang digunakan dalam penelitian ini berupa data saham ANTM sebanyak 2.699 record dari 02 Januari 2008 hingga 28 Desember 2018. Dari data tersebut dipilih entitas berupa tanggal dan harga penutupan saham yang kemudian digunakan dan diolah dalam penelitian ini. Data harga saham ANTM tersebut dapat dilihat pada Tabel 1.

Tabel1. Sample Data Harga Saham ANTM

\begin{tabular}{cc}
\hline Date & Close \\
\hline $28 / 12 / 2018$ & 765 \\
$27 / 12 / 2018$ & 770 \\
$26 / 12 / 2018$ & 770 \\
$21 / 12 / 2018$ & 770 \\
$20 / 12 / 2018$ & 765 \\
$19 / 12 / 2018$ & 760 \\
$18 / 12 / 2018$ & 750 \\
$17 / 12 / 2018$ & 730 \\
$14 / 12 / 2018$ & 755 \\
$13 / 12 / 2018$ & 765 \\
$12 / 12 / 2018$ & 755 \\
$11 / 12 / 2018$ & 755 \\
$10 / 12 / 2018$ & 720 \\
$07 / 12 / 2018$ & 725 \\
$06 / 12 / 2018$ & 735 \\
$05 / 12 / 2018$ & 740 \\
$04 / 12 / 2018$ & 710 \\
$03 / 12 / 2018$ & 735 \\
$30 / 11 / 2018$ & 615 \\
$29 / 11 / 2018$ & 625 \\
$15 / 11 / 2018$ & 670 \\
\hline
\end{tabular}




\section{Teknik Analisis Data}

Dari data yang telah dikumpulkan tersebut, kemudian dilakukan proses pengolahan data awal berupa tahapan pra pengolahan data. Adapun tahapan pra pengolahan data awal yang dilakukan dalam penelitian ini meliputi:

\section{Replace Missing Value}

Pada penelitian ini, pada pengolahan data awal yang pertama kali dilakukan adalah dengan melakukan replace missing value dikarenakan terdapat data yang masih missing value. (Hofmann, 2009) Replace missing value yaitu salah satu operator yang terdapat di data cleansing pada RapidMiner yang membantu menangani nilai null yang mungkin ada dalam data, yang dapat digunakan untuk menemukan nilai-nilai yang hilang dalam atribut atau serangkaian atribut dan merubahnya, dari nilai yang hilang ke nilai yang diinginkan

\section{Set Role}

Pada penelitian ini, set role operator digunakan untuk menjadikan atribut date sebagai atribut spesial yaitu sebagai atribut id

\section{Normalize}

Windowing merupakan salah satu teknik dalam menentukan data input dan data output dalam prediksi data runtun waktu dengan tipe univariat. Data univariat adalah distribusi data dengan melibatkan satu atribut atau variabel (Han, Kamber, \& Pei, 2012). Pada penelitian ini dilakukan normalisasi data menggunakan fungsi aktivasi binary sigmoid dengan jangkauan 0,1 s/d 0,9 . Perhitungan untuk binary sigmoid (logsig) didapat dari rumus sebagai berikut:

$$
y^{\prime}=\frac{x-x \min }{x \max -x \min } \times(0.9-0.1)+0.1
$$

Adapun ilustrasi dari fungsi binary sigmoid dapat dilihat pada Gambar 1 berikut.

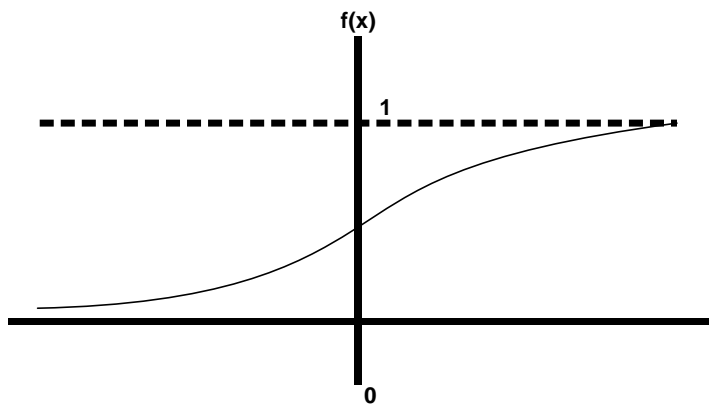

Gambar 1. Fungsi Binary Sigmoid

\section{Windowing}

Teknik windowing dilakukan untuk memecah atribut close pada data harga saham untuk kemudian dipecah menjadi 5 data input dan 1 data output. Data input merupakan data 5 hari sebelumnya dan data output adalah data 1 hari berikutnya

\section{Discrete Wavelet Transform}

Transformasi data dilakukan dengan mengaplikasikan operator Process Series yang kemudian dipilih metode tranformasi data dengan Discrete Wavelet Transform berupa Haar Wavelet.

Kemudian dari pengolahan data tersebut menghasilkan set data baru dan kemudian diolah dengan metode Neural Network menggunakan 10 Fold Cross Validation yang dipecah dalam data training dan data testing. Kemudian akan didapat nilai RMSEnya untuk kemudian dilakukan perbandingan antara metode Neural Network dengan metode yang diusulkan yaitu metode Neural Netwotk yang ditambahkan transformasi data dengan Discrete Wavelet Transform. Adapun prosesnya dapat dilihat pada Gambar 2 Sebagai berikut.

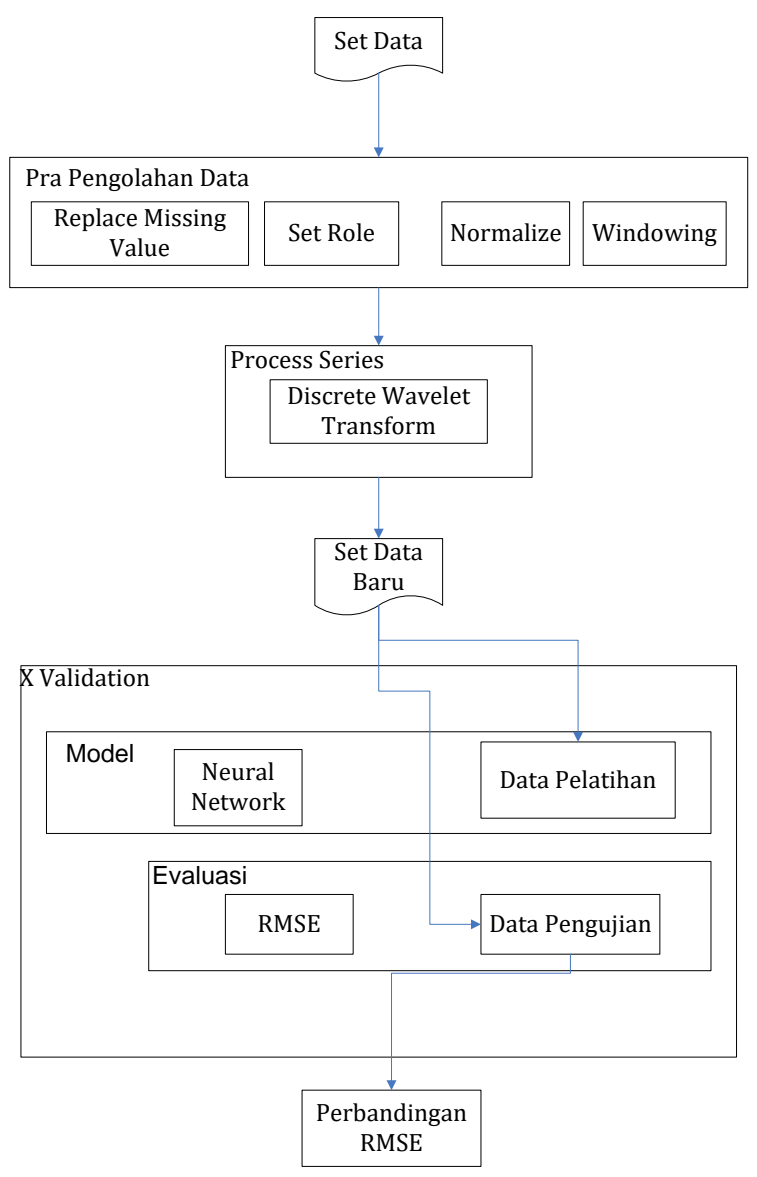

Gambar 2. Metode yang Diusulkan 


\section{HASIL PENELITIAN DAN PEMBAHASAN}

Pada penelitian ini, eksperimen yang dilakukan menggunakan tools Rapidminer 8.0. Tahapan eksperimen yang dilakukan adalah sebagai berikut:

1. Menyiapkan set data yang digunakan yaitu berupa data saham ANTM sebanyak 2.669 record

2. Melakukan proses pra pengolahan data dengan melakukan replace missing value, set role, normalize dan windowing

3. Melakukan transformasi data menggunakan Process Series dengan Discrete Wavelet Transform menggunakan Haar Wavelet dan memilih forward direction

4. Menerapkan metode Neural Network dengan memasukan parameter berupa Training Cycle, Learning Rate, Momentum dan Hidden Layer

5. Melakukan Training dan Testing terhadap metode usulan

6. Melakukan evaluasi dengan mencatat hasil RMSE dari eksperimen yang telah dilakukan. Adapun perhitungan hasil RMSE didapat dari rumus berikut.

$A=\sqrt{\frac{\sum_{i=1}^{N}\left(G i-G i^{\prime}\right)}{N}}$

Eksperimen pertama dilakukan dengan melakukan inisialisasi parameter Neural Network yang terdiri dari Training Cycle, Learning Rate, Momentum dan Hidden Layer dan normalisasi Neural Network menggunakan fungsi aktivasi Logsig atau Binary Sigmoid berupa jangkauan 0,1 sampai dengan -0,9. Hasil eksperimen ini kemudian dicatat ke dalam Tabel 2 berikut ini.

Tabel 2. Hasil Eksperimen Metode Neural Network (Fungsi Aktivasi Binary Sigmoid)

\begin{tabular}{ccccccc}
\hline $\begin{array}{c}\text { No } \\
\text { Perco } \\
\text { baan }\end{array}$ & $\begin{array}{c}\text { Hidd } \\
\text { en } \\
\text { Layer } \\
\text { Size }\end{array}$ & $\begin{array}{c}\text { Train } \\
\text { ing } \\
\text { Cycle }\end{array}$ & $\begin{array}{c}\text { Learn } \\
\text { ing } \\
\text { Rate }\end{array}$ & $\begin{array}{c}\text { Mom } \\
\text { entu } \\
\text { m }\end{array}$ & $\begin{array}{c}\text { Ho } \\
\text { riz } \\
\text { on }\end{array}$ & RMSE \\
\hline 1 & 1 & 500 & 0.3 & 0.2 & 1 & $\mathbf{0 , 0 2 2}$ \\
2 & 1 & 500 & 0.6 & 0.3 & 1 & $\mathbf{0 , 0 2 3}$ \\
3 & 3 & 1000 & 0.6 & 0.3 & 1 & $\mathbf{0 , 0 2 3}$ \\
4 & 3 & 1000 & 0.9 & 0.6 & 1 & $\mathbf{0 , 0 2 3}$ \\
5 & 3 & 500 & 0.9 & 0.6 & 1 & $\mathbf{0 , 0 2 3}$ \\
6 & 1 & 300 & 0.5 & 0.5 & 1 & $\mathbf{0 , 0 2 3}$ \\
7 & 1 & 300 & 0.1 & 0.3 & 1 & $\mathbf{0 , 0 2 4}$ \\
8 & 3 & 500 & 0.3 & 0.2 & 1 & $\mathbf{0 , 0 2 2}$ \\
9 & 3 & 500 & 0.6 & 0.3 & 1 & $\mathbf{0 , 0 2 3}$ \\
10 & 3 & 500 & 0.9 & 0.6 & 1 & $\mathbf{0 , 0 2 3}$ \\
\hline
\end{tabular}

Eksperimen selanjutnya dilakukan dengan menerapkan metode usulan berupa penerapan transformasi data Discrete Wavelet Transform dengan memilih metode Haar dan Forward Direction untuk transformasi Discrete Wavelet Transform nya. Selanjutnya menginisialisasi parameter Neural Network yang terdiri dari Training Cycle, Learning Rate, Momentum dan Hidden Layer dan normalisasi Neural Network menggunakan fungsi aktivasi Logsig atau Binary Sigmoid berupa jangkauan 0,1 sampai dengan -0,9. Hasil eksperimen ini kemudian dicatat ke dalam Tabel 3 Sebagai berikut.

Tabel 3. Hasil Eksperimen Metode Neural Network (Fungsi Aktivasi Binary

Sigmoid)+Discrete Wavelet Transform

\begin{tabular}{ccccccc}
\hline $\begin{array}{c}\text { No } \\
\text { Perc } \\
\text { obaa } \\
\mathbf{n}\end{array}$ & $\begin{array}{c}\text { Hidd } \\
\text { en } \\
\text { Layer } \\
\text { Size }\end{array}$ & $\begin{array}{c}\text { Train } \\
\text { ing } \\
\text { Cycle }\end{array}$ & $\begin{array}{c}\text { Lear } \\
\text { ning } \\
\text { Rate }\end{array}$ & $\begin{array}{c}\text { Mom } \\
\text { entu } \\
\text { m }\end{array}$ & $\begin{array}{c}\text { Horiz } \\
\text { on }\end{array}$ & RMSE \\
\hline 1 & 1 & 500 & 0.3 & 0.2 & 1 & $\mathbf{0 , 0 1 9}$ \\
2 & 1 & 500 & 0.6 & 0.3 & 1 & $\mathbf{0 , 0 1 8}$ \\
3 & 3 & 1000 & 0.6 & 0.3 & 1 & $\mathbf{0 , 0 1 8}$ \\
4 & 3 & 1000 & 0.9 & 0.6 & 1 & $\mathbf{0 , 0 1 9}$ \\
5 & 3 & 500 & 0.9 & 0.6 & 1 & $\mathbf{0 , 0 2}$ \\
6 & 1 & 300 & 0.5 & 0.5 & 1 & $\mathbf{0 , 0 1 8}$ \\
7 & 1 & 300 & 0.1 & 0.3 & 1 & $\mathbf{0 , 0 2}$ \\
8 & 3 & 500 & 0.3 & 0.2 & 1 & $\mathbf{0 , 0 2}$ \\
9 & 3 & 500 & 0.6 & 0.3 & 1 & $\mathbf{0 , 0 1 8}$ \\
10 & 3 & 500 & 0.9 & 0.6 & 1 & $\mathbf{0 , 0 2}$ \\
\hline
\end{tabular}

Gambar 3 di bawah ini merupakan arsitektur eksperimen prediksi harga saham menggunakan metode Neural Network dengan transformasi data Discrete Wavelet Transform dengan parameter 1 Hidden Layer, Training Cycle 300, dan Learning Rate dan Momentum masingmasing 0,5 yang menghasilkan RMSE sebesar 0,018 .

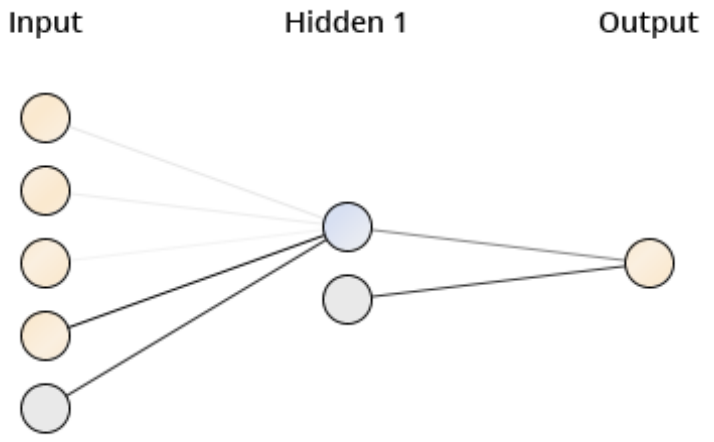

Gambar 3. Arsitektur Neural Network + Discrete Wavelet transform 
Dari eksperimen metode Neural Network dan Neural Network Discrete Wavelet Transform, terdapat beberapa perbedaan hasil RMSE yang kemudian dilakukan pencatatan hasil $R M S E$ nya ke dalam Tabel 4 sebagai berikut.

Tabel 4. Perbandingan Hasil RMSE NN

\begin{tabular}{cc}
\multicolumn{2}{c}{ dan NN+DWT } \\
\hline $\begin{array}{c}\text { Neural } \\
\text { Network }\end{array}$ & $\begin{array}{c}\text { Neural } \\
\text { Network } \\
\text { + DWT }\end{array}$ \\
\hline $\mathbf{0 , 0 2 2}$ & $\mathbf{0 , 0 1 9}$ \\
$\mathbf{0 , 0 2 3}$ & $\mathbf{0 , 0 1 8}$ \\
$\mathbf{0 , 0 2 3}$ & $\mathbf{0 , 0 1 8}$ \\
$\mathbf{0 , 0 2 3}$ & $\mathbf{0 , 0 1 9}$ \\
$\mathbf{0 , 0 2 3}$ & $\mathbf{0 , 0 2}$ \\
$\mathbf{0 , 0 2 3}$ & $\mathbf{0 , 0 1 8}$ \\
$\mathbf{0 , 0 2 4}$ & $\mathbf{0 , 0 2}$ \\
$\mathbf{0 , 0 2 2}$ & $\mathbf{0 , 0 2}$ \\
$\mathbf{0 , 0 2 3}$ & $\mathbf{0 , 0 1 8}$ \\
$\mathbf{0 , 0 2 3}$ & $\mathbf{0 , 0 2}$ \\
\hline
\end{tabular}

Berdasarkan data pada Tabel 3 di atas, maka dapat digambarkan dalam Gambar 4 di bawah ini bagaimana selisih dari perbandingan hasil RMSE dari kedua eksperimen tersebut.

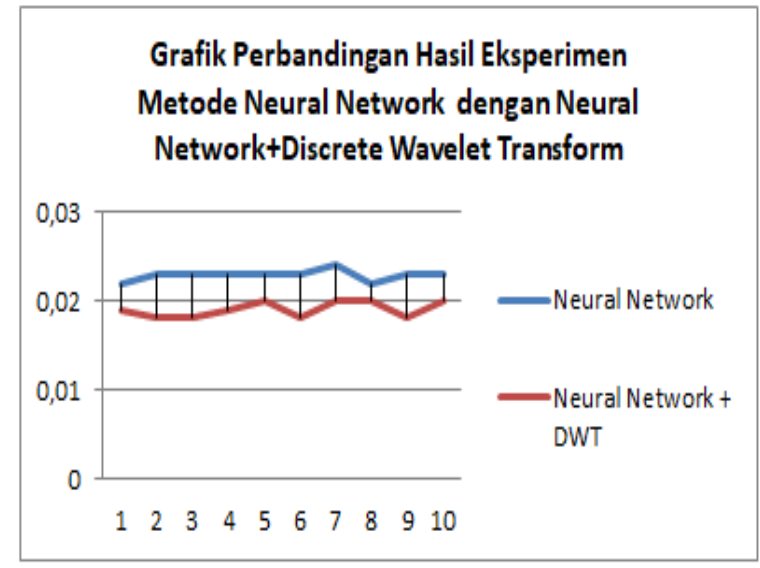

Gambar 4. Grafik Perbandingan RMSE Neural Network (Fungsi Aktivasi Binary Sigmoid dan Neural Network (Fungsi Aktivasi Binary Sigmoid)+ Discrete Wavelet Transform

\section{SIMPULAN DAN SARAN}

\section{Simpulan}

Metode usulan pada penelitian ini diterapkan dengan melakukan transformasi data Discrete Wavelet Transform untuk mengembangkan metode Neural Network dengan fungsi aktivasi binary sigmoid. Metode usulan ini digunakan untuk melakukan prediksi terhadap data saham ANTM yang kemudian berdasarkan eksperimen yang telah dilakukan terbukti dapat meningkatkan hasil prediksi harga saham. Hal ini dilakukan dengan melihat perbandingan hasil RMSE yang dihasilkan. Pada eksperimen menggunakan metode Neural Network fungsi aktivasi binary sigmoid, dari 10 eksperimen yang dilakukan, menghasilkan nilai RMSE terkecil sebesar 0,022 dan RMSE rata-rata sebesar 0,0229. Sedangkan untuk metode usulan yaitu metode Neural Network fungsi aktivasi binary sigmoid dengan transformasi data Discrete Wavelet Transform dihasilkan RMSE terkecil sebesar 0,018 dan RMSE rata-rata sebesar 0,019 sehingga terdapat selisih nilai RMSE sebesar 0,0039.

\section{Saran}

Berdasarkan kesimpulan penelitian, maka untuk penelitian di masa mendatang dapat dilakukan pengembangan terhadap metode Neural Network dengan metode lainnya untuk dapat lebih meningkatkan performa Neural Network sehingga menghasilkan prediksi yang lebih akurat lagi.

\section{DAFTAR REFERENSI}

A, Adebiyi, A., K, Charles, A., O, Marion, A., \& 0, Sunday, 0. (2012). Stock Price Prediction using Neural Network with Hybridized Market Indicators. Journal of Emerging Trends in Computing and Information Sciences, 3(1), 1-9.

Anbazhagan, S., \& Kumarappan, N. (2014). Dayahead deregulated electricity market price forecasting using neural network input featured by DCT. Energy Conversion and Management, 78, 711-719. https://doi.org/10.1016/j.enconman.2013.1 1.031

Beaumont, A. N. (2014). Data transforms with exponential smoothing methods of forecasting. International Journal of Forecasting, 30(4), 918-927. https://doi.org/10.1016/j.ijforecast.2014.03. 013

Bennett, C. J., Stewart, R. a., \& Lu, J. W. (2014). Forecasting low voltage distribution network demand profiles using a pattern recognition based expert system. Energy, 67, 200-212. https://doi.org/10.1016/j.energy.2014.01.0 32 
Han, J., Kamber, M., \& Pei, J. (2012). Data Mining: Concepts and Techniques.

Hofmann, M. (2009). Data Mining and Knowledge Discovery Series.

Kirchgässner, G., \& Wolters, J. (2007). Introduction to Modern Time Series Analysis. https://doi.org/10.1007/978-3-540-732914

Montgomery, D. C. (2008). Introduction to Time Series Analysis and Forecasting.

Ouyang, Y., \& Yin, H. (2014). A neural gas mixture autoregressive network for modelling and forecasting FX time series. Neurocomputing, 135,

171-179. https://doi.org/10.1016/j.neucom.2013.12.0 37
Rajput, V., \& Bobde, S. (2016). Stock Market Forecasting Techniques: Literature Survey. International Journal of Computer Science and Mobile Computing, 5(6), 500-506. Retrieved from www.ijcsmc.com

Sundararajan, D. (2015). Discrete Wavelet Transform: A Signal Processing Approach. In Discrete Wavelet Transform: A Signal Processing Approach. https://doi.org/10.1002/9781119113119

Suryani, I. (2015). Penerapan Exponential Smoothing untuk Transformasi Data dalam Meningkatkan Akurasi Neural Network pada Prediksi Harga Emas. 1(2). 